\title{
Treatment of hepatitis $C$ virus genotype 4 in the DAA era
}

Antonio Di Biagio ${ }^{{ }^{*}} \mathbb{D}$, Lucia Taramasso 2,3 and Giovanni Cenderello ${ }^{4}$

\begin{abstract}
The recently approved interferon-free DAA (direct antiviral agents) regimens have shown not only to be effective in terms of sustained virological response (SVR) rates (>90\%) but also well tolerated in most hepatitis C virus (HCV) infected patients. Nevertheless HCV genotypes are different and only a small percentage of trials consider genotype 4 (GT4), which was associated with lower rates of SVR compared with other genotypes before the arrival of the DAA's. In this review, we discuss the efficacy of DAA therapy in GT4 HCV infection with specific reference to more recent studies, including those conducted in a 'field-practice' scenario. Overall, DAA-based regimens appear more effective also in the poorly-explored setting of patients with HCV GT4 infection. Despite an overall limited number of patients was evaluated, favorable results are being derived from studies on ombitasvir/paritaprevir/ritonavir, sofosbuvir and velpatasvir, whether or not in association with voxilaprevir, and with the new combined therapy glecaprevir + pibentasvir.
\end{abstract}

\section{Introduction}

The introduction of direct antiviral agents (DAAs) in clinical practice has undoubtedly represented a landmark advance in the treatment of hepatitis $\mathrm{C}$ virus infection (HCV) $[1,2]$. With these therapies, the wide majority (90-95\%) of HCV-infected patients can now be successfully cured $[2,3]$. Less attention was paid to genotype 4 (GT4) HCV in clinical trials and field-practice studies compared with other genotypes [4]. Current estimates state that this GT accounts for $13 \%$ of all HCV infections [5]. The bulk of the GT4 infection is found in the Middle East, Northern Africa and Sub-Saharan Africa, with 93\% of HCV patients in Egypt being infected by this genotype $[5,6]$. In Europe, prevalence of GT4 infection is more variable (up to $16 \%$ in Italy in HIV co-infected patients, $8 \%$ in Spain, $14 \%$ in Belgium); however, migration flows from Northern Africa are likely to increase the prevalence of GT4 HCV infection in the next years [5, 7]. Importantly, GT4 is a historically difficult to treat genotype, and a trend towards lower rates of sustained virological response (SVR) in GT4 has been signaled also with DAA treatment [1]. A recent excellent review by Hathorn and Elsharkawy has extensively discussed current evidence on

\footnotetext{
* Correspondence: antonio.dibiagio@hsanmartino.it

${ }^{1}$ Infectious Diseases Clinic, Policlinico Hospital San Martino, L.go R. Benzi n

10, 16132 Genoa, Italy

Full list of author information is available at the end of the article
}

the treatment of GT4 HCV infection in the DAA era, with a focus on clinical trials [4]. However, the advancement of clinical research in HCV treatments proceeds at such a high pace that continuous update is necessary [4]. In particular, information on patients with renal disease - who often present $\mathrm{HCV}$ infection and who are particularly challenging to treat- appears required.

In this review, we discuss the efficacy of DAA therapy in GT4 HCV infection with specific reference to more recent studies, including those conducted in a 'field-practice' scenario.

\section{Methods}

Papers for consideration in the present review were retrieved via a PubMed query, using "DAA AND HCV AND genotype 4" as keywords. Research was last updated on 22nd Sept 2017. No other limitations were applied. In total, 247 papers met these criteria. Papers were then selected for inclusion in the present manuscript according to their relevance for the topic, as judged by the Authors. When possible, studies with specific reference to GT4 infection were selected. Overall, 17 clinical trials (one in patients undergoing hemodialysis), 17 'field-practice' experiences (two of which on patients with renal disease) and one meta-analysis of real-world data were reported [Table 1]. 
Table 1 Key results of the clinical trials included in the present analysis

\begin{tabular}{|c|c|c|c|}
\hline $\begin{array}{l}\text { Clinical trial or field } \\
\text { experience }\end{array}$ & $\mathrm{n}^{\circ}$ of patients with G4-infection & Treatment & SVR rate in GT4 patients \\
\hline Ruane 2015 [8] & 34 & $\mathrm{SOF}+\mathrm{RBV}$ & $68-93 \%$ \\
\hline Feld 2015 [9] & 116 & SOFNEL & $100 \%$ \\
\hline Curry 2015 [10] & 8 & SOFNEL & $100 \%$ \\
\hline Gane 2016 [11] & 17 & SOFNEL + VOX & $58 \%$ \\
\hline Bourliere 2017 [12] & 41 (POLARIS-1 + POLARIS-4) & SOFNEL + VOX & $97 \%$ \\
\hline Colombo 2017 [13] & 10 & SOF/LDV & $100 \%$ \\
\hline Kholi 2015 [14] & 21 & SOF/LDV & $95 \%$ \\
\hline Buti 2017 [15] & 40 & $\mathrm{SMV} / \mathrm{SOF}$ & $100 \%$ \\
\hline El Raziky 2017 [16] & 63 & SMV/SOF & $92 \%$ \\
\hline Kwo 2017 [17] & 37 & $\mathrm{EBR}+\mathrm{GZR}$ & $89 \%$ \\
\hline Waked [18] & 160 & OBV/PTV/R/RBV & $93-94 \%$ \\
\hline Hézode 2015 [19] & 135 & $\mathrm{OBV} / \mathrm{PTV} / \mathrm{r} \pm \mathrm{RBV}$ & 100\% with RBV, 91\% without RBV \\
\hline Forns [20] & 16 & GLI/PIB & $100 \%$ \\
\hline Kwo [42] & 22(SURVEYOR-I and SURVEYOR-II) & GLI/ PIB & $100 \%$ \\
\hline Asselah [21] & $\begin{array}{l}\text { SURVEYOR-II Part 4, ENDURANCE-4 } \\
\text { and ENDURANCE-2) }\end{array}$ & GLI/ PIB & $\begin{array}{l}\text { 93\% } 8 \text { week treatment } \\
99 \% 12 \text { week treatment }\end{array}$ \\
\hline Yakoot [22] & $\begin{array}{l}120 \text { (randomized } 60 \text { in } 12 \text { weeks } \\
\text { regimen and } 60 \text { in response tailored } \\
\text { regimen) }\end{array}$ & $\mathrm{SOF}+\mathrm{DAC}$ & $\begin{array}{l}96.7 \% \text { in the fixed regimen } \\
98.4 \% \text { in the response tailored regimen }\end{array}$ \\
\hline El-Khayat [23] & $\begin{array}{l}551 \text { cirrotic patients ( } 432 \text { naïve, } 119 \\
\text { treatment experienced) }\end{array}$ & $\mathrm{SOF}+\mathrm{DAC}+\mathrm{RBV}$ & $\begin{array}{l}\text { 92\%in naïve } \\
87 \% \text { in experienced }\end{array}$ \\
\hline Willemse [24] & 53 (naïve and IFN experienced) & $\mathrm{SOF}+\mathrm{SIM}$ & $92 \%$ \\
\hline Degre [25] & 87, IFN experienced & $\mathrm{SOF}+\mathrm{SIM} \pm \mathrm{RBV}$ & $87.4 \%$ \\
\hline Elsharkawy 2017 [26] & $\begin{array}{l}8742(F 3) \\
5667(F 3)\end{array}$ & $\begin{array}{l}\text { SOF/peg/IFN-RBV } \\
\text { SOF/RBV }\end{array}$ & $\begin{array}{l}94 \% \\
79 \%\end{array}$ \\
\hline Asselah 2017 [27] & 67 naïve, F0-F2 & $\mathrm{SIM}+\mathrm{PEG}$ IFN & $97 \%$ \\
\hline loannou [28] & 135 (two arm: 104, 31) & $\mathrm{SOF} / \mathrm{LDV} \pm \mathrm{RBV}$ and OBV/PTV/r $\pm \mathrm{RBV}$ & $89.6 \%$ \\
\hline Crespo [29] & 152 (two arm:130 and 122) & $\mathrm{SOF} / \mathrm{LDV} \pm \mathrm{RBV}$ and $\mathrm{OBV} / \mathrm{PTV} / \mathrm{r} \pm \mathrm{RBV}$ & 95.4 and $96.2 \%$ \\
\hline Welzel [30] & 53 & $\mathrm{OBV} / \mathrm{PTV} / \mathrm{r} \pm \mathrm{RBV}$ & $100 \%$ \\
\hline Perello [31] & 87 (73\% cirrhosis, 35\% treatment naïve) & $\mathrm{OBV} / \mathrm{PTV} / \mathrm{r} \pm \mathrm{RBV}$ & $100 \%$ \\
\hline Petta 2017 [32] & 17 & $\mathrm{OBV} / \mathrm{PTV} / \mathrm{r} \pm \mathrm{RBV}$ & $94 \%$ \\
\hline Wedemeyer 2017 [33] & 112,19 cirrhosis & $\mathrm{OBV} / \mathrm{PTV} / \mathrm{r} \pm \mathrm{RBV}$ & $96,5 \%$ \\
\hline Komatsu [34] & 26 & $\mathrm{EBR}+\mathrm{GZR}$ & $100 \%$ \\
\hline Maria 2017 [35] & 7 & $\mathrm{SOF} \pm \mathrm{SIM}$ or $\mathrm{DAC}$ or $\mathrm{LDV} \pm \mathrm{RBV}$ & $100 \%$ \\
\hline Hezode 2016 [36] & 215 & $\mathrm{SOF}+\mathrm{DAC}$ & $91 \%$ \\
\hline Babatin 2017 [37] & $\begin{array}{l}40 \\
35 \% \text { cirrhotic; treatment-experienced } \\
52.5 \%\end{array}$ & $\begin{array}{l}\text { SOF + DAC } \\
+ \text { RBV }\end{array}$ & $100 \%$ \\
\hline Abad 2017 [38] & 35 & $\mathrm{OBV} / \mathrm{PTV} / \mathrm{r}$ & $100 \%$ \\
\hline Ponziani 2017 [46] & 8 & OBV/PTV/r & $100 \%$ \\
\hline Manns 2016 [43] & 37 & SOF/LDV + RBV & $81 \%$ \\
\hline
\end{tabular}




\section{Clinical trials Sofosbuvir}

In an open-label study at single center, 60 patients were enrolled and completed treatment with Sofosbuvir plus ribavirin for 12 weeks (31 patients) or 24 weeks (29 patients). SVR 12 was achieved by 21 of the 31 patients (68\%) receiving 12 weeks of treatment, and by 27 of 29 patients (93\%) receiving 24 weeks of treatment [8].

\section{Sofosbuvir/velpatasvir}

In clinical trials, the association of sofosbuvir and velpatasvir (SOF/VEL) showed promising results. In a phase 3, double-blind, placebo-controlled study, 116 patients with GT4 infection (52/116 treatment experienced, 27/ 116 cirrhotic) were treated with such association, reaching 100\% SVR [9]. The same association was also investigated in 267 patients with decompensated cirrhosis in the ASTRAL-4 study [10]. In this difficult-to-treat population, serious adverse events occurred in $19 \%$ of patients who received 12 weeks of SOF/VEL, $16 \%$ of those who received 12 weeks of SOF/VEL plus ribavirin (RBV), and $18 \%$ of those who received 24 weeks of SOF/VEL. Only eight patients infected with GT4 have been included in the study and all achieved SVR.

\section{Sofosbuvir/velpatasvir/voxilaprevir}

In a multicenter, phase II study on sofosbuvir, velpatasvir and voxilaprevir (SOF/VEL/VOX), Gane et al. have investigated the optimal regimen for patients with GT1, 2, 3, 4 or 6 infections [11]. In total, 128 patients were enrolled; of these, 17 presented GT4 infection (10 treatment-naive and 7 with prior therapy). In total, only 7 patients experienced a virological failure, of whom 3 were GT4 infected. All three patients were treatment-naïve, two were non-cirrhotic patients treated for 6 weeks, while the third was a cirrhotic patient treated for 8 weeks. Additional data come from the POLARIS-1 and POLARIS-4 studies, in which 22 and 19 patients infected with HCV GT4 have been included, respectively, and were treated with SOF/VEL/ VOX [12]. All patients had been previously treated with a DAA-containing regimen; 21/22 subjects in POLARIS-1 and 19/19 in POLARIS-4 achieved SVR. The only treatment failure, in POLARIS-1, occurred in a cirrhotic patient who had been previously treated with SOF and ledipasvir (SOF/LDV) for 12 weeks in 2015, while no other patient with GT4 experienced treatment failure with this triple drug regimen.

\section{Sofosbuvir/ledipasvir}

In an international, randomized, phase II, open-label study, the safety and efficacy of SOF/LDV in fixed-dose combination tablet, for 12 or 24 weeks were compared in 114 kidney transplant recipients (69\% treatment-naïve) with GT1 (91\%) or GT4 infection (9\%) [13]. Remarkably, all patients, regardless of treatment duration, achieved SVR12. Serious adverse events were reported in 13 patients $(11 \%)$, and one patient permanently discontinued treatment due to an adverse event (syncope). In a proof-of-concept, single-center, open-label, phase 2a trial, SOF/LDV was also studied exclusively in patients infected with GT4 [14]. In this study, only 21 patients have been included, but 20 of them achieved SVR after 12 weeks of SOF/LDV (95\%), including seven patients with cirrhosis, while the only patient who failed achieving SVR was non-adherent to treatment. No patients discontinued therapy due to adverse events and no grade 3 or 4 adverse events related to study medications were reported.

\section{Simeprevir}

Two recently published clinical trials investigated the efficacy of simeprevir (SMV) + SOF in GT4 patients: PLUTO and OSIRIS studies $[15,16]$. The PLUTO study is a phase III open-label trial, that investigated the efficacy of 12-weeks treatment with SMV + SOF in GT4-infected patients either naïve or experienced to antiviral therapy [15]. In total, 40 patients were evaluated; of these, 27 (68\%) were treatment-experienced and 7 (18\%) had compensated cirrhosis. Noteworthy, all patients achieved SVR12, while adverse events, all of mild-to-moderate intensity, were reported in 20/40 (50\%) of patients. The other recently published trial evaluating the efficacy and safety of SMV + SOF was the OSIRIS study, in which GT4 HCV-infected patients with F0-F4 fibrosis were treated for 8 or 12 weeks [16]. In total, 63 patients (33 treatment-naïve and 30 Peg-IFN/RBV-experienced) were randomly assigned to receive either 8 weeks (Group A1, $n=20$ ) or 12 weeks (Group A2, $\mathrm{n}=20$ ) of treatment. Patients with compensated cirrhosis (METAVIR F4) received 12 weeks of treatment (Group B, $n=23$ ). Overall, $92 \%$ of patients achieved SVR12; corresponding figures were $75 \%$ in Group A1 and $100 \%$ in both groups A2 and B. The five patients who did not achieve SVR12 experienced viral relapse during the first 32 days following treatment and were all prior Peg-IFN/RBV null responders. No patients discontinued due to treatment-emergent adverse events.

\section{Elbasvir and grazoprevir}

In a phase III, randomized, controlled, open-label trial, the effects of 12 or 16 weeks of treatment with elbasvir (EBR) and grazoprevir (GZR) in fixed-dose combination tablet, with or without twice-daily RBV, were evaluated in 420 treatment-experienced patients with GT1, GT4 or GT6 infection [17]. Patients were randomly assigned (1:1:1:1) to treatment with EBR + GZR once daily, with or without twice-daily RBV, for 12 or 16 weeks. Thirty-seven patients were GT4 (47\% cirrhotic). Of them, 24 received 12 weektreatment ( 9 without and 15 with RBV) and 13 were treated for 16 weeks (5 without and 8 with RBV). The 
global proportion of SVR12 in patients infected with GT4 was $88.9 \%$, with the highest rate of failure, $12.5 \%$, in patients treated for 12 weeks without RBV and the lowest, $0 \%$, in patients treated for 16 weeks with RBV.

\section{Ombitasvir/paritaprevir/ritonavir}

The efficacy of OBV/PTV/r in GT4 have also been explored in a multicentre phase $2 \mathrm{~b}$, randomised, open-label combination trial (PEARL-I), in which 135 patients with GT4 (49/135 treatment experienced) have been included and randomly assigned to receive once-daily OBV/PTV/r for 12 weeks with or without RBV [18]. SVR was achieved by $100 \%$ of patients treated with the addition of RBV and by $91 \%$ of those treated without. Only three treatmentnaive patients who received OBV/PTV/r without RBV experienced virological failure, and they were all infected with GT4. One patient in OBV/PTV/r experienced an aspartate aminotranferase (AST) elevation of grade $\geq 3$ and three patients in OBV/PTV/r + RBV experienced a bilirubin elevation of grade 3.

In the AGATHE-II a phase 3, open label, 182 patients with GT4 were screened, of whom 160 were eligible for inclusion; SVR was achieved by $94 \%$ (94/100) of patients without cirrhosis, and 97\% (30/31) patients with cirrhosis treated for 24 weeks; Instead SVR was achieved by $93 \%$ $(27 / 29)$ of patients with cirrhosis treated for 24 weeks [19].

\section{Glecaprevir/pibrentasvir}

The recently approved once-daily, ribavirin-free, DAA regimen of glecaprevir co-formulated with pibrentasvir, has been studied for pangenotypic $\mathrm{HCV}$ treatment. In the phase 3 study EXPEDITION-1, 16 GT4 infected patients with compensated cirrhosis had $100 \%$ sustained response after 12 weeks of treatment [20], and the same (100\% SVR) was also found in SURVEYOR-I and SURVEYOR-II phase II, dose-ranging trials, despite the presence of baseline polymorphisms, in 22 GT4 infected patients [20]. In 3 separate phase 3 trials performed in patients without cirrhosis, (SURVEYOR-II Part 4, ENDURANCE-4 and ENDURA NCE-2), 43/46 GT4 patients treated for 8 weeks and 75/76 patients treated for 12 weeks achieved SVR [21].

\section{Daclatasvir}

A recent paper reports a successful experience in treating patients with GT4 chronic infection with generic formulations of SOF and daclatasvir (DAC) [22]; in this open-label randomized non-inferiority study, in which all enrolled patients were non-cirrhotic and had GT4 chronic infection, two different schedules of treatment were compared. Patients were divided into two groups: a fixed duration group, in which all patients received 12 weeks of therapy, and a virological guided response group, in which patients could receive either 8 or 12 weeks of therapy, based on a virological response. Indeed, patients were treated for 8 weeks only if they achieved a very rapid virological response (vRVR), defined as an undetectable viral load after 2 weeks of treatment (patients not reaching vRVR were continuing treatment at 12 weeks). This trial showed a SVR12 of 96.67\% (ITT) in the group with a fixed duration and of 98.33\% in the virological guided response group. No major adverse events were observed, while a shorter treatment period could increase adherence, reduce the drug exposure and optimize resource use, reducing the cost of about one third [23]. A second multicentre, open-label trial, conducted exclusively in GT4 patients, describes the experience with SOF and DAC in patients with more advanced stages of disease. Five hundred fifty-one cirrhotic patients (468 Child A; 83 Child B) were enrolled to receive SOF and DAC plus weight-adjusted RBV for 12 weeks. Among them, 432 were naïve to IFN-treatment, whereas 119 were treatment-experienced. In the intention to treat analysis, the overall 12 week SVR rate was $92 \%$ in naïve patients, but lower, $68 \%$, in patients presenting more than one negative predictor of response (treatment experienced and Child B cirrhotic). The corresponding figures in per protocol analysis were 94 and $79 \%$. [23].

\section{'Field-practice' experiences Simeprevir}

In a multicenter, 'field-practice', retrospective study, Willemse et al. have specifically assessed the effectiveness of treatment with SOF and SMV, with or without RBV, in a cohort of GT4 HCV patients [24]. A total of 53 patients, either naïve or experienced, were included. SVR rate was 92\% (49/53). All four failures showed virological relapse and were not treated with RBV. In another experience, conducted in Belgium, Degrè et al. evaluated 87 GT4-infected treatment-naïve or IFN-experienced patients treated with SOF and SMV with or without RBV (41\% had severe fibrosis, and 59\% cirrhosis) [25]. The overall SVR12 rate was $87.4 \%$, while patients treated with and without RBV had rates of 87.9 and $87 \%$, respectively. On the other hand, patients with advanced fibrosis and patients with cirrhosis had SVR12 rates of 94.4 and $82.4 \%$, respectively. SVR12 rates in treatmentnaïve patients and in INF-experienced patients were 78.9 and $89.7 \%$. In most cases, treatment failure occurred in patients with cirrhosis and severe disease. The treatment was well tolerated and no patient discontinued treatment due to adverse events.

In a multicenter study, Asselah et al. investigated the efficacy and safety of 12-week SMV plus peg-IFN/RBV in 67 treatment-naive patients with GT4 infection and F0-F2 fibrosis [26]. Patients with early virologic response ( $\mathrm{HCV}$ RNA $<25 \mathrm{IU} / \mathrm{mL}$ ) at Week 2 and HCV RNA undetectable at weeks 4 and 8 were eligible to stop all treatment at the end of week $12(n=34)$, otherwise Peg-IFN/RBV therapy was continued to week 24 . All patients in the 12-week 
group showed undetectable HCV RNA at end of treatment, and 97\% (33/34) achieved SVR12. No new safety signals were reported.

\section{Sofosbuvir}

A large National Treatment Programme was launched in Egypt practice in October 2014. Patients who were eligible for treatment were classified according to their eligibility for interferon therapy: Group 1 were treated with triple therapy for 12 weeks and Group 2 (interferon ineligible) were treated with Sofosbuvir and ribavirin for 24 weeks. The study analysed the data from the first 14,409 patients who completed follow-up to 12 weeks post HCV treatment. SVR12 rates were $94 \%$ and 78.7 in Group 1 and Group 2, respectively [27].

\section{Sofosbuvir/ledipasvir}

A large 'field-practice' retrospective analysis $(N=17,487)$ of the Veterans Affairs National Health Care System has evaluated the effectiveness of SOF/LDV and OBV/PTV/r in the treatment of 135 patients with HCV GT4 infection [28]. Of them, 104 received $\mathrm{SOF} / \mathrm{LDV} \pm \mathrm{RBV}$ and 31 $\mathrm{OBV} / \mathrm{PTV} / \mathrm{r} \pm \mathrm{RBV}$. Overall, SVR12 rate was $89.6 \%$ (95\% CI 82.8-93.9), with a higher incidence in treatment-experienced subjects (93.5\%). Interestingly, $96.4 \%$ of GT4-infected, OBV/PTV/r-treated patients achieved SVR12, compared with $87.6 \%$ of those receiving SOF/ LDV. A smaller, but prospective, Spanish cohort study confirmed the above-mentioned findings [29]. In more details, GT4-infected patients treated with $\mathrm{OBV} / \mathrm{PTV} / \mathrm{r}+$ $\operatorname{RBV}(n=122)$ or SOF/LDV \pm RBV $(n=130)$ were evaluated. SVR12 rates were $96.2 \%$ with $\mathrm{OBV} / \mathrm{PTV} / \mathrm{r}+\mathrm{RBV}$ and $95.4 \%$ with SOF/LDV \pm RBV. In cirrhotic patients, SVR12 was $91.2 \%$ with OBV/PTV/r + RBV and $93.2 \%$ with $\mathrm{SOF} / \mathrm{LDV} \pm \mathrm{RBV}$. Rates of severe adverse events and associated discontinuations were 5.7 and $2.5 \%$ in the OBV/ $\mathrm{PTV} / \mathrm{r}$ sub-cohort, respectively and 4.6 and $0.8 \%$ in the SOF/LDV sub-cohort, respectively; in most cases, these events were likely due to RBV administration (e.g., anemia).

\section{Ombitasvir/paritaprevir/ritonavir}

In addition to the above-mentioned experiences (see previous paragraph, [25-28]), in another 'field-practice' study, from the German Hepatitis C Registry, Welzel et al. investigated the effectiveness of OBV/PTV/r $\pm \mathrm{RBV}$ in 53 patients infected by GT4: all of them achieved SVR12 [29]. Similar findings were reported in a Spanish early access program, the effectiveness and safety of OBV/ $\mathrm{PTV} / \mathrm{r}$ was retrospectively investigated [30]. In total, 291 , either infected $69.8 \%$ by GT1 or $30.2 \%$ by GT4 (73\% with cirrhosis, 35\% treatment-naïve) were evaluated. The rate of SVR12 was $96.2 \%$ for GT1 and $100 \%$ for GT4, with no statistical difference according to viral genotype. Thirty patients (10.3\%) experienced serious adverse events, leading to discontinuation in six cases, once again due in most cases to RBV treatment. Although the number of GT4 patients was small, a prospective observational study, with collected data from ABACUS compassionate-use program, has investigated the use of OBV/PTV/r with dasabuvir plus RBV for GT1 and OBV/PTV/r plus RBV for GT4 infection (24 weeks of treatment) in patients with cirrhosis at high risk of decompensation, while approval of these regimens was pending in Italy [31]. In total, 762 patients were evaluated. Of them, only 17 had GT4 and 16 (94\%) achieved SVR. The number of patients infected by GT4 was too low to allow a sub-group analysis, but, in the global population of this study, logistic regression analyses identified that bilirubin concentrations of less than 2 $\mathrm{mg} / \mathrm{dL}$ were associated with SVR12 (odds ratio [OR] 4.76 [95\% CI 1.83-12.3]; $p=0.001$. Overall, the SVR rate was $96 \% ; 23 \%$ of patients experienced adverse events, with asthenia being the most commonly reported (5\%).

A meta-analysis of real world data of a total of 5158 patients (5046 with HCV GT1 and 112 GT4 infection), treated with $\mathrm{OBV} / \mathrm{PTV} / \mathrm{r} \pm \mathrm{DSV} \pm \mathrm{RBV}$ across 25 primary publications, showed an overall SVR of $96.8 \%$ (95\% CI, 96.3 97.3) [32]. Cohort data included fewer patients with GT4 infection and cirrhosis, and breakdown data was available for 19 of them; 99\% (95\%CI, 82.3-100) of them achieved SVR. The rate of response was similar for non-cirrhotic patients with GT4 infection, as 100\% (51/51) achieved SVR.

\section{Elbasvir/gazoprevir}

The independent analysis of the US Food and Drug Administration has shown that $100 \%$ (26 out of 26) patients with HCV GT4 infection and NS5A polymorphisms who received EBR + GZR with or without RBV achieved SVR12 [33].

\section{Daclatasvir}

In a Swedish experience, the outcome of IFN-free treatment for HCV relapse after liver transplantation has been documented [34]. In total, 93 patients with $\mathrm{HCV}$ relapse after liver transplantation received SOF-based treatment either in combination or not with SMV, DAC or LDV with or without RBV. Of these, 7 patients were infected by GT4 HCV, and all of them achieved SVR12.

Good results were also recorded in the ATU French cohort, composed by 176 GT4 patients treated with SOF and DAC. All the patients enrolled had advanced stages of liver fibrosis and no other treatment option, at the time of the study. The overall SVR 12 rate was $90 \%$, with the highest rate $(97 \%)$ reached in cirrhotic patients treated with RBV, a the lowest $(88 \%)$ in those treated without RBV [35]. 
Babatin et al. reported their real life experience in treating 96 GT4 patients, 56 received SOF + SMV \pm RBV (group 1) whereas $40 \mathrm{SOF}+\mathrm{DAC} \pm \mathrm{RBV}$ for 12 weeks (group 2). Liver cirrhosis was present in 53.6 and $35.0 \%$ of group 1 and 2, respectively. Furthermore, $43.2 \%$ in group 1 and $52.5 \%$ in group 2 already failed a previous IFN-treatment. All patients achieved SVR 12 (100\% SVR), adverse events were reported in $32 \%$ of the patients but none discontinued treatment [36].

\section{Special populations \\ Renal impairment}

A recent multicenter trial investigated the efficacy and safety of OBV/PTV/r and dasabuvir with/without ribavirin in 35 GT1-4 HCV-infected patients undergoing hemodialysis [37]. In this difficult-to-treat population, all patients archived SVR, without any relevant safety concern. The most relevant side effect was anemia, which was more marked in patients on ribavirin $(n=17)$ and requiring increase of the dose of erythropoiesis-stimulating agents. With specific reference to patients with renal impairment Ponziani et al. also reported the outcomes of a series of 10 subjects on hemodialysis therapy infected by GT1a, 1b, or $4 \mathrm{HCV}$ that received $\mathrm{OBV} / \mathrm{PTV} / \mathrm{r}$ (+ DSV in GT1), with or without RBV [37]. All patients achieved SVR12, and therapy was well tolerated.

The OBV/PTV/r regimen does not require dose modification for those with end-stage renal disease, with or without dialysis.

\section{End stage liver disease}

The efficacy and safety of SOF/LDV association have been also explored in patients with advanced cirrhosis in Child-Pugh stage $\mathrm{B}$ or $\mathrm{C}$ in an open-label study conducted at 34 sites in Europe [38]. Patients were randomly assigned to 12 or 24 weeks of treatment with $\mathrm{SOF} / \mathrm{LDV}+\mathrm{RBV}$ and were stratified in subgroups on the basis of liver transplantation receipt or not and Child-Pugh stage. Thirty-seven patients with HCV GT4 were enrolled and SVR was achieved in 30 subjects (81\%), with higher success rates in the groups treated for 24 weeks.

\section{Discussion}

The wide majority of clinical trials and 'field-practice' experiences on HCV treatment are focused on GT1 and GT3, which represent the most frequently-observed genotype worldwide and the most challenging to treat, respectively. Nevertheless, a large proportion of patients is infected by GT4, but this population is often under-represented in clinical trials. Moreover, in the era of peg-IFN and RBV, GT4 was one of the more difficult to treat genotypes, with SVR rates of
$43-70 \%$ [38]. Therefore, many pre-treated patients, either non-responders or relapsers, are still to be treated in the current era.

On the other hand, data emerging from the analysis of DAA-treated cohorts show an overall SVR rate $>90 \%$, even in the most difficult to cure populations such as patients affected by liver cirrhosis. Available evidence on GT4 therapy is overall scant. However, studies conducted to date - both in the experimental and the 'field-practice' setting - have showed promising cure rates up to $100 \%$, even in treatment-experienced or cirrhotic GT4 patients, when administered for 12 weeks courses. Very short treatments of only 6 or 8 weeks seem not yet fully optimized, since also non-cirrhotic naïve patients failed to reach satisfactory percentages of cure in some contexts, even if the number of studied subjects is still low [23]. In such scenario, the desire to spare a few weeks of treatment risks may in turn be associated with high risk of retreatment or onset of resistances. Moreover, all DAAs appear very well tolerated, with discontinuation rates usually below $5 \%$, and side effects often linked more to RBV co-administration than to DAA tolerability issues [27, 32].

Due to the period of analysis of the literature review no more recent combinations have been included. With these combinations the success rates reach $97-99 \%$ success. This review is limited in being tightly focused on effectiveness; as such, it does not assess adverse reactions, quality of life, or any other long-term factors [39-41].

The results of this analysis show the pivotal role of $\mathrm{OBV} / \mathrm{PTV} / \mathrm{r}$, which is characterized by a SVR rate higher than $90 \%$ in all categories of patients $[17,27-30]$ and studied for GT4 also in the context of advanced kidney disease [35, 36]. Likewise SOF/LDV and SMV + SOF achieve high success rates $[11,14-16,21-26,28,34-$ $36]$. We must also consider promising results obtained with EBR + GZR [17, 32], glicaprevir/biprentasvir [19, $20,42]$ and SOF/VEL in association or not with VOX [8-11]. The data analysed in the present review clearly show that there is not one regimen standing out compared to others, but that there are many regimens that can be safely used and that are effective for GT4 treatment. An approach to GT4 treatment guided by current guidelines is advisable [43-45], with continuous updating of the revolution of the therapeutic scenario currently underway.

\section{Conclusions}

The introduction of DAA therapy clearly revolutionized the approach to treatment of $\mathrm{HCV}$ infection. Current evidence shows high SVR rates and an excellent tolerability profile also in patients with GT4 infection, including those with renal impairment. Although larger trials 
are needed to further confirm these findings, DAAs grant the cure to thousands of patients and give them a new hope to definitively clear HCV GT4 infection, not only in newly infected patients, but also in who underwent to IFN and RBV-related side effects and failed to be cured.

\section{Acknowledgements}

We thank Dr. Luca Giacomelli for his contribution to this work.

\section{Funding}

none.

\section{Availability of data and materials}

all the trials and clinical studies included in this review are published in journals indexed in PubMed (available at www.pubmed.com).

\section{Authors' contributions}

Dr. ADB: selection of papers to be included in the review, revision of selected papers, ideation and revision of the work. Dr. LT: revision of selected papers, and article writing. Dr. GC: selection of papers to be included in the review, revision of selected papers, revision and coordination of the work, final approval of the version to be published.

\section{Ethics approval and consent to participate}

Not applicable.

\section{Consent for publication}

Not applicable.

\section{Competing interests}

The authors declare that they have no competing interests.

\section{Publisher's Note}

Springer Nature remains neutral with regard to jurisdictional claims in published maps and institutional affiliations.

\section{Author details}

'Infectious Diseases Clinic, Policlinico Hospital San Martino, L.go R. Benzi n 10, 16132 Genoa, Italy. ${ }^{2}$ Department of Health Sciences (DISSAL), University of Genova and Infectious Disease Clinic, Via Pastore n 1, 16136 Genoa, Italy. ${ }^{3}$ Infectious Diseases Unit, Department of Internal Medicine, 'Fondazione IRCCS Ca' Granda Ospedale Maggiore Policlinico, Via Francesco Sforza 35, Milan, Italy. ${ }^{4}$ Infectious Disease Unit, EO Ospedali Galliera, via Mura delle Cappuccine n 14, 16128 Genoa, Italy.

Received: 22 November 2017 Accepted: 13 November 2018

Published online: 22 November 2018

\section{References}

1. Arias A, Aguilera A, Soriano V, Benítez-Gutiérrez L, Lledó G, Navarro D, Treviño A, Otero E, Peña JM, Cuervas-Mons V, de Mendoza C. Rate and predictors of treatment failure to all-oral HCV regimens outside clinical trials. Antivir Ther. 2017;22:307-12.

2. Arends JE, Kracht PA, Hoepelman Al. European study Group for Viral Hepatitis (ESGVH)2. Performance of hepatitis C virus (HCV) direct-acting antivirals in clinical trials and daily practice. Clin Microbiol Infect. 2016;22:846-52.

3. Majumdar A, Kitson MT, Roberts SK. Systematic review: current concepts and challenges for the direct-acting antiviral era in hepatitis $C$ cirrhosis. Aliment Pharmacol Ther. 2016;43:1276-92.

4. Hathorn E, Elsharkawy AM. Management of hepatitis C genotype 4 in the directly acting antivirals era. BMJ Open Gastroenterol. 2016;3:e000112.

5. Gower E, Estes C, Blach S, Razavi-Shearer K, Razavi H. Global epidemiology and genotype distribution of the hepatitis C virus infection. J Hepatol. 2014; 61(Suppl 1):45-57.

6. Abd Elrazek AE, Bilasy SE, Elbanna AE, Elsherif AE. Prior to the oral therapy, what do we know about HCV-4 in Egypt: a randomized survey of prevalence and risks using data mining computed analysis. Medicine (Baltimore). 2014;93:e204.
7. D'Arminio Monforte A, Cozzi-Lepri A, Ceccherini-Silberstein F, De Luca A, Lo Caputo S, Castagna A, Mussini C, Cingolani A, Tavelli A, Shanyinde M, Gori A, Girardi E, Andreoni M, Antinori A. Puoti M; Icona Foundation and Hepalcona Study Group. Access and response to direct antiviral agents (DAA) in HIV-HCV co-infected patients in Italy: Data from the Icona cohort. PLoS One. 2017;12:e0177402.

8. Ruane PJ, Ain D, Stryker R, Meshrekey R, Soliman M, Wolfe PR, et al. Sofosbuvir plus ribavirin for the treatment of chronic genotype 4 hepatitis $C$ virus infection in patients of Egyptian ancestry. J of Hepatology. 2015;62:1040-6.

9. Feld JJ, Jacobson IM, Hézode C, Asselah T, Ruane PJ, Gruener N, Abergel A, Mangia A, Lai CL, Chan HL, Mazzotta F, Moreno C, Yoshida E, Shafran SD, Towner WJ, Tran TT, Osinusi A, Svarovskaia E, Zhu Y, Brainard DM, JG MH, Agarwal K, Zeuzem S. ASTRAL-1 investigators. Sofosbuvir and Velpatasvir for HCV genotype 1, 2, 4, 5, and 6 infection. N Engl J Med. 2015;373:2599-607.

10. Curry MP, O'Leary JG, Bzowej N, Muir AJ, Korenblat KM, Fenkel JM, Reddy KR, Lawitz E, Flamm SL, Schiano T, Teperman L, Fontana R, Schiff E, Fried M, Doehle B, An D, McNally J, Osinusi A, Brainard DM, McHutchison JG, Brown RS $\mathrm{Jr}$, Charlton M. ASTRAL-4 investigators. Sofosbuvir and Velpatasvir for HCV in Patients with Decompensated Cirrhosis. N Engl J Med. 2015;373:2618-28.

11. Gane EJ, Kowdley KV, Pound D, Stedman CA, Davis M, Etzkorn K, Gordon SC, Bernstein D, Everson G, Rodriguez-Torres M, Tsai N, Khalid O, Yang JC, Lu S, Dvory-Sobol H, Stamm LM, Brainard DM, McHutchison JG, Tong M, Chung RT, Beavers K, Poulos JE, Kwo PY, Nguyen MH. Efficacy of Sofosbuvir, Velpatasvir, and GS-9857 in patients with hepatitis C virus genotype 2, 3, 4, or 6 infections in an open-label, phase 2 trial. Gastroenterology. 2016;151:902-9.

12. Bourlière M, Gordon SC, Flamm SL, Cooper CL, Ramji A, Tong M, Ravendhran N, Vierling JM, Tran TT, Pianko S, Bansal MB, de Lédinghen V, Hyland RH, Stamm LM, Dvory-Sobol H, Svarovskaia E, Zhang J, Huang KC, Subramanian GM, Brainard DM, McHutchison JG, Verna EC, Buggisch P, Landis CS, Younes ZH, Curry MP, Strasser SI, Schiff ER, Reddy KR, Manns MP, Kowdley KV, Zeuzem S. POLARIS-1 and POLARIS-4 Investigators. Sofosbuvir, Velpatasvir, and Voxilaprevir for Previously Treated HCV Infection. N Engl J Med. 2017;376:2134-46.

13. Colombo M, Aghemo A, Liu H, Zhang J, Dvory-Sobol H, Hyland R, Yun C, Massetto B, Brainard DM, McHutchison JG, Bourlière M, Peck-Radosavljevic M, Manns M, Pol S. Treatment with Ledipasvir-Sofosbuvir for 12 or 24 weeks in kidney transplant recipients with chronic hepatitis $C$ virus genotype 1 or 4 infection: a randomized trial. Ann Intern Med. 2017;166:109-17.

14. Kohli A, Kapoor R, Sims Z, Nelson A, Sidharthan S, Lam B, Silk R, Kotb C, Gross C, Teferi G, Sugarman K, Pang PS, Osinusi A, Polis MA, Rustgi V, Masur H, Kottilil S. Ledipasvir and sofosbuvir for hepatitis C genotype 4: a proof-of-concept, singleCentre, open-label phase 2a cohort study. Lancet Infect Dis. 2015;15:1049-54.

15. Buti M, Calleja JL, Lens S, Diago M, Ortega E, Crespo J, Planas R, RomeroGómez M, Rodríguez FG, Pascasio JM, Fevery B, Kurland D, Corbett C, Kalmeijer R, Jessner W. Simeprevir in combination with sofosbuvir in treatment-naïve and -experienced patients with hepatitis $C$ virus genotype 4 infection: a phase III, open-label, single-arm study (PLUTO). Aliment Pharmacol Ther. 2017:45:468-75.

16. El Raziky M, Gamil M, Ashour MK, Sameea EA, Doss W, Hamada Y, Van Dooren G, DeMasi R, Keim S, Lonjon-Domanec I, Hammad R, Hashim MS, Hassany M, Waked I. Simeprevir plus sofosbuvir for eight or 12 weeks in treatment-naïve and treatment-experienced hepatitis $C$ virus genotype 4 patients with or without cirrhosis. J Viral Hepat. 2017;24:102-10.

17. Kwo P, Gane EJ, Peng CY, Pearlman B, Vierling JM, Serfaty L, Buti M, Shafran S, Stryszak P, Lin L, Gress J, Black S, Dutko FJ, Robertson M, Wahl J, Lupinacci L, Barr E, Haber B. Effectiveness of Elbasvir and Grazoprevir combination, with or without ribavirin, for treatment-experienced patients with chronic hepatitis C infection. Gastroenterology. 2017;152:164-75.

18. Hézode C, Asselah T, Reddy KR, Hassanein T, Berenguer M, FleischerStepniewska K, Marcellin P, Hall C, Schnell G, Pilot-Matias T, Mobashery N, Redman R, Vilchez RA, Pol S. Ombitasvir plus paritaprevir plus ritonavir with or without ribavirin in treatment-naive and treatment-experienced patients with genotype 4 chronic hepatitis C virus infection (PEARL-I): a randomised, open-label trial. Lancet. 2015;385:2502-9.

19. Waked I, Shiha G, Qaqish RB, Esmat G, Yosry A, et al. Ombitasvir, paritaprevir, and ritonavir plus ribavirin for chronic hepatitis C virus genotype 4 infection in Egyptian patients with or without compensated cirrhosis (AGATHE-II): a multicentre, phase 3, partly randomised open label trial. Lancet Gastroenterol Hepatol. 2016;1:36-44.

20. Hézode Forns X, Lee SS, Valdes J, Lens S, Ghalib R, Aguilar H, Felizarta F, Hassanein $T$, Hinrichsen $H$, Rincon D, Morillas $R$, Zeuzem $S$, Horsmans $Y$, Nelson DR, Yu Y, Krishnan P, Lin CW, Kort JJ, Mensa FJ. Glecaprevir plus 
pibrentasvir for chronic hepatitis $C$ virus genotype 1, 2, 4, 5, or 6 infection in adults with compensated cirrhosis (EXPEDITION-1): a single-arm, open-label, multicentre phase 3 trial. Lancet Infect Dis. 2017;17:1062-8.

21. Asselah T, Kowdley KV, Zadeikis N, Wang S, Hassanein T, Horsmans $Y$, Colombo M, Calinas F, Aguilar H, de Ledinghen V, Mantry PS, Hezode C, Marinho RT, Agarwal K, Nevens F, Elkhashab M, Kort J, Liu R, Ng TI, Krishnan P, Lin CW, Mensa FJ. Efficacy of Glecaprevir/Pibrentasvir for 8 or 12 weeks in patients with hepatitis $C$ virus genotype 2, 4, 5, or 6 infection without cirrhosis. Clin Gastroenterol Hepatol. 2017. https://doi.org/10.1016/j.cgh. 2017.09.027 [Epub ahead of print].

22. Yakoot M, Abdo AM, Abdel-Rehim S, Helmy S. Response tailored protocol versus the fixed 12 weeks course of dual Sofosbuvir/Daclatasvir treatment in Egyptian patients with chronic hepatitis C Genotype-4 infection: a randomized, open-label. Non-inferiorityTrial EBioMedicine. 2017;21:182-7.

23. El-Khayat H, Fouad Y, Mohamed HI, El-Amin H, Kamal EM, Maher M, Risk A. Sofosbuvir plus daclatasvir with or without ribavirin in 551 patients with hepatitis C-related cirrhosis, genotype 4. Aliment Pharmacol Ther. 2018:47:674-9.

24. Willemse $S B$, Baak LC, Kuiken SD, van der Sluys VA, Lettinga KD, van der Meer JT, Depla AC, Tuynman H, van Nieuwkerk CM, Schinkel CJ, Kwa D, Reesink HW, van der Valk M. Sofosbuvir plus simeprevir for the treatment of HCV genotype 4 patients with advanced fibrosis or compensated cirrhosis is highly efficacious in real life. J Viral Hepat. 2016;23:950-4.

25. Degré $D$, Sersté $T$, Lasser $L$, Delwaide J, Starkel $P$, Laleman $W$, Langlet $P$, Reynaert H, Bourgeois S, Vanwolleghem T, Negrin Dastis S, Gustot T, Geerts A, Van Steenkiste C, de Galocsy C, Lepida A, Orlent H, Moreno C. Sofosbuvir in combination with Simeprevir +/- ribavirin in genotype 4 hepatitis $C$ patients with advanced fibrosis or cirrhosis: a real-world experience from Belgium. PLoS One. 2017;12:e0170933.

26. Asselah T, Moreno C, Sarrazin C, Gschwantler M, Foster GR, Craxí A, Buggisch P, Sanai F, Bicer C, Lenz O, Van Dooren G, Nalpas C, Lonjon-Domanec I, Schlag M, Buti M. Efficacy of a 12-week Simeprevir plus Peginterferon/ribavirin (PR) regimen in treatment-Naiive patients with hepatitis $\mathrm{C}$ virus (HCV) genotype 4 (GT4) infection and mild-to-moderate fibrosis displaying early on-treatment Virologic response. PLoS One. 2017;12:e0168713.

27. Ioannou GN, Beste LA, Chang MF, Green PK, Lowy E, Tsui II, Su F, Berry K. Effectiveness of Sofosbuvir, Ledipasvir/Sofosbuvir, or Paritaprevir/ritonavir/Ombitasvir and Dasabuvir regimens for treatment of patients with hepatitis $\mathrm{C}$ in the veterans affairs National Health Care System. Gastroenterology. 2016;151:457-71.

28. Crespo J, Calleja JL, Fernández I, Sacristan B, Ruiz-Antorán B, Ampuero J, Hernández-Conde M, García-Samaniego J, Gea F, Buti M, Cabezas J, Lens S, Morillas RM, Salcines JR, Pascasio JM, Turnes J, Sáez-Royuela F, Arenas J, Rincón D, Prieto M, Jorquera F, Sanchez Ruano JJ, Navascués CA, Molina E, Moya AG, Moreno-Planas JM. Spanish Group for the Study of the Use of Direct-acting Drugs Hepatitis C Collaborating Group. Real-World Effectiveness and Safety of Oral Combination Antiviral Therapy for Hepatitis C Virus Genotype 4 Infection. Clin Gastroenterol Hepatol. 2017;15:945-9.

29. Welzel TM, Hinrichsen $H$, Sarrazin C, Buggisch P, Baumgarten A, Christensen S, Berg T, Mauss S, Teuber G, Stein K, Deterding K, van Bömmel F, Heyne R, John C, Zimmermann T, Lutz T, Schott E, Hettinger J, Kleine H, König B, Hüppe D, Wedemeyer H. Real-world experience with the all-oral, interferonfree regimen of ombitasvir/paritaprevir/ritonavir and dasabuvir for the treatment of chronic hepatitis C virus infection in the German hepatitis C registry. J Viral Hepat. 2017;24:840-9.

30. Perelló C, Carrión JA, Ruiz-Antorán B, Crespo J, Turnes J, Llaneras J, Lens S, Delgado M, García-Samaniego J, García-Paredes F, Fernández I, Morillas RM, Rincón D, Porres JC, Prieto M, Lázaro Ríos M, Fernández-Rodríguez C, Hermo JA, Rodríguez M, Herrero Jl, Ruiz P, Fernández JR, Macías M, Pascasio JM, Moreno JM, Serra MÁ, Arenas J, Real Y, Jorquera F, Calleja JL. Spanish Collaborative Group for the Study of the Use of Hepatitis C Direct-Acting Drugs. Effectiveness and safety of ombitasvir, paritaprevir, ritonavir \pm dasabuvir \pm ribavirin: An early access programme for Spanish patients with genotype 1-4 chronic hepatitis C virus infection. J Viral Hepat. 2017;24:226-37.

31. Petta S, Marzioni M, Russo P, Aghemo A, Alberti A, Ascione A, Antinori A, Bruno R, Bruno S, Chirianni A, Gaeta GB, Giannini EG, Merli M, Messina V, Montilla S, Perno CF, Puoti M, Raimondo G, Rendina M, Silberstein FC, Villa E, Zignego AL, Pani L, Craxi A. ABACUS study group; AIFA team. Ombitasvir, paritaprevir, and ritonavir, with or without dasabuvir, plus ribavirin for patients with hepatitis $C$ virus genotype 1 or 4 infection with cirrhosis (ABACUS): a prospective observational study. Lancet Gastroenterol Hepatol. 2017;2:427-34.
32. Wedemeyer H, Craxí A, Zuckerman E, Dieterich D, Flisiak R, Roberts SK, Pangerl A, Zhang Z, Martinez M, Bao Y, Calleja JL. Real-world effectiveness of Ombitasvir/Paritaprevir/ritonavir \pm Dasabuvir \pm ribavirin in patients with HCV genotype 1 or 4 infection: a meta-analysis. J Viral Hepat. 2017;24:936-43.

33. Komatsu TE, Boyd S, Sherwat A, Tracy L, Naeger LK, O'Rear JJ, Harrington PR. Regulatory analysis of effects of hepatitis C virus NS5A polymorphisms on efficacy of Elbasvir and Grazoprevir. Gastroenterology. 2017;152:586-97.

34. Maria C, Michael S, Susanne C, Catarina S, Ola W. INF-free sofosbuvir-based treatment of post-transplant hepatitis C relapse - a Swedish real life experience. Scand J Gastroenterol. 2017;52:585-8.

35. Hezode C, Abergel A, Chas J, et al. Sustanined virologic response to daclatasvir and sofosbuvir with or without ribavirin, among patients in the French daclatasvir ATU programme infected with HCV genotypes 4,5,6. J Hepatol. 2016;64:S133-42 Available at: http://www.journal-of-hepatology. eu/article/S0168-8278(16)01471-9/abstract

36. Babatin MA, Alghamdi AS, Albenmousa A, Alaseeri A, Aljarodi M, Albiladi H, Alsahafi A, Almugharbal M, Alothmani HS, Sanai FM, Bzeizi Kl. Efficacy and safety of Simeprevir or Daclatasvir in combination with Sofosbuvir for the treatment of hepatitis C genotype 4 infection. J Clin Gastroenterol. 2017; 52(5):452-7 [Epub ahead of print].

37. Abad S, Vega A, Hernández E, Mérida E, de Sequera P, Albalate M, Macías N, Milla M, López-Gómez JM. Universal sustained viral response to the combination of Ombitasvir/Paritaprevir/ritonavir and Dasabuvir with/ without ribavirin in patients on hemodialysis infected with hepatitis $\mathrm{C}$ virus genotypes 1 and 4. Am J Nephrol. 2017;45:267-72.

38. Ponziani FR, Siciliano M, Lionetti $R$, Pasquazzi C, Gianserra L, D'Offizi G, Gasbarrini A, Pompili M. Effectiveness of Paritaprevir/ritonavir/Ombitasvir/ Dasabuvir in hemodialysis patients with hepatitis C virus infection and advanced liver fibrosis: case reports. Am J Kidney Dis. 2017;70:297-300.

39. Abdel-Moneim A, Aboud A, Abdel-Gabbar M, Zanaty MI, Ramadan M. A sofosbuvir-based quadruple regimen is highly effective in HCV type 4-infected Egyptian patients with DAA treatment failure. J Hepatol. 2018;68:1313-5.

40. Abdel-Moneim A, Aboud A, Abdel-Gabbar M, Zanaty M, Ramadan M. Retreatment efficacy of Sofosbuvir/Ombitasvir/Paritaprevir/ritonavir + ribavirin for hepatitis C virus genotype 4 patients. Dig Dis Sci. 2018;63(5):1341-7.

41. Abdel-Moneim A, Aboud A, Abdel-Gabaar M, Zanaty Ml, Ramadan M. Efficacy and safety of sofosbuvir plus daclatasvir with or without ribavirin: large real-life results of patients with chronic hepatitis $C$ genotype 4 . Hepatol Int. 2018;12(4):348-55.

42. Kwo PY, Poordad F, Asatryan A, Wang S, Wyles DL, Hassanein T, Felizarta F, Sulkowski MS, Gane E, Maliakkal B, Overcash JS, Gordon SC, Muir AJ, Aguilar H, Agarwal K, Dore GJ, Lin CW, Liu R, Lovell SS, Ng TI, Kort J, Mensa FJ. Glecaprevir and pibrentasvir yield high response rates in patients with $\mathrm{HCV}$ genotype 1-6 without cirrhosis. J Hepatol. 2017;67:263-71.

43. Antaki N, Craxi A, Kamal S, et al. The neglected hepatitis C virus genotypes 4, 5 and 6: an international consensus report. Liver Int. 2010;30:342-55.

44. American Association for the Study of Liver Diseases (AALSD). HCV Guidance: Recomendations for Testing, Managing and Treating Hepatitis C. https://www.hcvguidelines.org. Accessed on 05 March 2018.

45. European Association for the Study of the Liver (EASL). EASL Recommendations on Treatment of Hepatitis C 2016. http://www.easl.eu/ medias/cpg/HCV2016/English-report.pdf. Accessed on 05 March 2018.

46. Manns M, Samuel D, Gane EJ, Mutimer D, Mc Caughan G, Buti M, Prieto M, Calleja JL, Peck-Radosavljevic M, Müllhaupt B, Agarwal K, Angus P, Yoshida EM, Colombo M, Rizzetto M, Dvory-Sobol H, Denning J, Arterburn S, Pang PS, Brainard D, JG MH, Dufour JF, Van Vlierberghe H, van Hoek B. Forns X; SOLAR-2 investigators. Ledipasvir and sofosbuvir plus ribavirin in patients with genotype 1 or 4 hepatitis C virus infection and advanced liver disease: a multicentre, open-label, randomised, phase 2 trial. Lancet Infect Dis. 2016; 16:685-97. 